\title{
Multilayered vacuum-arc nanocomposite TiN/ZrN coatings before and after annealing: Structure, properties, first-principles calculations
}

\author{
Alexander Pogrebnjak ${ }^{\mathrm{a} *}$, Volodymyr Ivashchenko ${ }^{\mathrm{b}}$, Oleksandr Bondar ${ }^{\mathrm{a}, \mathrm{e}}$, Vyacheslav Beresnev ${ }^{\mathrm{c}}$, \\ Oleg Sobol $^{\mathrm{d}}$, Karol Załęski ${ }^{\mathrm{e}}$, Stefan Jurga ${ }^{\mathrm{e}}$, Emerson Coy ${ }^{\mathrm{e}}$, Piotr Konarski ${ }^{\mathrm{f}}$, Bogdan Postolnyi ${ }^{\mathrm{a}, \mathrm{g}}$ \\ a Sumy State University, 40007, R.-Korsakova 2, Sumy, Ukraine \\ ${ }^{\mathrm{b}}$ Frantsevych Institute for Problems of Material Science, NAS of Ukraine, 3, Krzhyzhanovsky Str., 03142 Kyiv, Ukraine \\ c V.N. Karazin Kharkiv National University, 4 Svobody Sq., Kharkiv 61022, Ukraine \\ d National Technical University "KhPI", 2, Kyrpychova str., 61002 Kharkiv, Ukraine \\ e NanoBioMedical Centre, Adam Mickiewicz University, ul. Umultowska 85, 61-614 Poznań, Poland \\ ${ }^{\mathrm{f}}$ Tele and Radio Research Institute, ul. Ratuszowa 11, 03-450 Warsaw, Poland \\ ${ }^{g}$ IFIMUP and IN-Institute of Nanoscience and Nanotechnology, Department of Physics and Astronomy, University of Porto, 687, Rua do Campo Alegre, 4169-007 Porto, \\ Portugal
}

\section{A R T I C L E I N F O}

\section{Keywords:}

TiN/ZrN

Multilayers

Hardness

Nanoscale

Nanocrystals

First-principles calculations

\begin{abstract}
A B S T R A C T
Nanoscale multilayered TiN/ZrN films were deposited using sequential vacuum-arc deposition of $\mathrm{Ti}$ and $\mathrm{Zr}$ targets in a nitrogen atmosphere. Studies of film's properties were carried out using various modern methods of analysis, such as XRD, STEM, HRTEM, SIMS combined with results of nanoindentation and tribological tests. To interpret the mechanical properties of the deposited multilayer films first-principles calculations of $\mathrm{TiN}(111)$, $\mathrm{ZrN}(111)$ structures and $\mathrm{TiN}(111) / \mathrm{ZrN}(111)$ multilayer were carried out. To study the influence of thermal annealing, several samples were annealed in air at the temperature $700{ }^{\circ} \mathrm{C}$. All deposited samples were highly polycrystalline with quite large $20-25 \mathrm{~nm}$ crystals. The crystalline planes were very ordinated and demonstrated an excellent coordinated growth. The nanohardness and elastic modulus of non-annealed coatings reached $42 \mathrm{GPa}$ and $348 \mathrm{GPa}$, respectively. Annealing in air at the temperature $700{ }^{\circ} \mathrm{C}$ led to partial oxidation of the multilayered coatings, however hardness of the non-oxidized part of the coatings remained as high, as for initial coatings. All deposited coatings demonstrate good wear resistance.
\end{abstract}

\section{Introduction}

Physical-mechanical and tribological properties of the traditional materials, being used in high-temperature aggressive medium, are relatively unsatisfactory in many applications, which leads to necessity of developing new materials with enhanced wear and corrosion resistance as well as high temperatures influence resistance, etc. Intensive studies devoted to the development of composite materials based on nitrides of refractory metals, are carried out intensively nowadays. Such compounds can be used as matrix or as reinforcing filler in the form of fibers or plates. These composite materials are characterized by low specific mass, durability and wear resistance, and demonstrate possibility of complex shapes details formation. Because of high strength and heat resistance, they can be used in aero and space industry as high-temperature construction materials, for gas turbines, petrol engines, heat exchangers production, etc.

Multilayer nanoscale coatings on the base of nitrides of transition metals are well-known for their unique physical-mechanical properties, as well as good corrosion resistance [1-4]. Vacuum-arc evaporation of cathode is a promising deposition method, which allows fabrication of multilayered coatings on the base of nitrides and carbides of transition metals [5-8]. A varying the deposition conditions, such as gas pressure in the deposition chamber, bias potential, bilayer thickness, etc. allows to fabricate coatings with very high hardness [9-11], good wear coefficient and resistance to wear, oxidation [12-17] and to corrosion $[18,19]$ as well as with good electrical properties [20,21]. As it was reported in the previous papers [22,23], coatings on the (Ti,Zr)N base have high hardness $42-48 \mathrm{GPa}$, as well as resistance to oxidation under the influence of high temperatures $1170{ }^{\circ} \mathrm{C}$ [24-28]. It is also known, that nanoscale multilayer coatings on the base of TiN, CrN, ZrN, and MoN have higher hardness in comparison with single-layer ones with the hardness equal to 24-38 GPa [25,29-31].

The main purpose of the present work was to study multilayer nanoscale TiN/ZrN coatings, their physical-mechanical properties, as well

\footnotetext{
* Corresponding author.

E-mail address: alexp@i.ua (A. Pogrebnjak).
} 
as their microstructure before and after annealing at $700{ }^{\circ} \mathrm{C}$ in air. Firstprinciples investigations were performed to interpret the experimental results. Such combination of experimental studies and computational modeling has been never provided before.

\section{Experimental Procedure}

The multilayer TiN/ZrN coatings were deposited using vacuum-arc evaporation method from two targets [23], one of which contained titanium and the second contained zirconium (Fe $<0.12 \%$, $\mathrm{C}<0.05 \%$, Si $<0.08 \%$, N $<0.04 \%$, O $<0.1, \mathrm{H}<0.008$, concentration of $\mathrm{Ti}$ or $\mathrm{Zr}$ was in the range 99.5-99.9). Ion-plasma deposition or, in other words, coating's deposition using vacuum arc cathode evaporation is a very promising way of fabrication of protective coatings. The coatings were deposited on the A 570 Grade 36 steel $(\mathrm{Ra}=0.09 \mu \mathrm{m}$, size was $15 \times 15 \times 2.5 \mathrm{~mm}$ ) polished substrates under different deposition modes. Total thickness of the deposited coatings was $19 \mu \mathrm{m}$, while bilayer thickness was about $39 \mathrm{~nm}$, thus total number of bilayers was 500 . The arc current during deposition was $100 \mathrm{~A}$, the nitrogen pressure in the deposition chamber was $0.4 \mathrm{~Pa}$, the distances from evaporators to substrate were $250 \mathrm{~mm}$, the substrate temperature was $250 \ldots 350{ }^{\circ} \mathrm{C}$, deposition rate of $\mathrm{ZrN}$ and TiN layers was around $3 \mathrm{~nm} / \mathrm{s}$ and $2 \mathrm{~nm} / \mathrm{s}$, respectively. Negative bias potential $-200 \mathrm{~V}$ was applied to the substrates, it allowed fabrication of homogeneous coatings with good enough planarity. Thermal annealing of the samples were done in the vacuum chamber, pressure in it was $0.0013 \mathrm{~Pa}$, while the pressure of the incoming oxygen atmosphere was $0.4 \mathrm{~Pa}$. Annealing time was $1 \mathrm{~h}$.

Structure-phase investigations were done using the DRON-3M and Ultima IV "Rigaku" diffractometers in $\mathrm{Cu}-\mathrm{K}_{\alpha}$ radiation. Surface morphology and structural properties of the films were studied using JEOL ARM 200F high-resolution transmission electron microscope (200 kV) with an EDX analyzer. The cross sections and lamellas for TEM investigations were prepared by focused ion beam (FIB) processing and observation system JEOL JIB-4000. A broad carbon thin film was deposited on the sample surface to protect the area of interest from damage during the FIB milling and observation with $\mathrm{Ga}^{+}$ion beam. The $\mathrm{Ga}^{+}$ion beam of adjustable acceleration voltage $5-30 \mathrm{kV}$ was used to prepare lamellae down to electron transparency. Secondary ion mass spectroscopy (SIMS) measurements were carried out using SAJW-05 analyzer equipped with Physical Electronics 06-350E ion gun and quadrupole mass analyzer QMA-410 Balzers. An argon ion beam of $1.72 \mathrm{keV}$ was used at $45^{\circ}$ incidence angle, digitally scanning over $1 \mathrm{~mm} \times 1 \mathrm{~mm}$ area. For depth profile analysis, the positive secondary ion currents emitted from the central part of the scanned area (around $15 \%$ electronic gate) were selected. Hardness and elastic modulus of the coatings were measured on HYZITRON TI 950 Tribometer. This device allows performing continuous measurement of the contact stiffness via a superimposed alternating current signal during loading, which provides a continuous measurement of the elastic modulus (E) and hardness $(\mathrm{H})$ as functions of indenter penetration depth $(\mathrm{L})$ during a single loading segment. All indentations were done with a Berkovich diamond tip of a nominal radius equal to $\sim 340 \mathrm{~nm}$. At least ten indentations were made on each sample. The load was continuously increasing to a maximum $10 \mathrm{mN}$.

\section{Computational Aspects}

To clarify a role of the interface in the strength enhancement of the deposited TiN/ZrN nanolayered films we performed first principles investigations of $\mathrm{TiN}(111), \mathrm{ZrN}(111)$ and $\mathrm{TiN}(111) / \mathrm{ZrN}(111)$ structures. The initial 96 atoms hexagonal supercells with the B1 structure (space group Fm-3m, No. 225) were considered to calculate the total energy and tensile stress-strain relations of these structures. All the supercells consisted of 12 layers aligned perpendicularly to the (111) direction in the $\mathrm{B} 1$ lattice. In the case of the $\operatorname{TiN}(111) / \mathrm{ZrN}(111)$ multilayer, the supercell represented six layers of TiN(111) and six layers of $\mathrm{ZrN}(111)$. The motivation of such a choice of the supercells was the fact that the deposited TiN/ZrN nanolayered films had the (111) preferable crystallite orientation.

First-principles calculations were carried out using the QuantumESPRESSO code [32] using the periodic boundary conditions. Vanderbilt ultra-soft pseudo-potentials were used to describe the electron-ion interaction [33]. The semi-core states were treated as valence states. To describe exchange-correlation energy, the generalized gradient approximation (GGA) of Perdew et al. [34] was employed. The criterion of convergence for the total energy was $10^{-6} \mathrm{Ry} /$ formula unit. To speed up convergence, each eigenvalue was convoluted with a Gaussian with a width of $0.02 \mathrm{Ry}(0.272 \mathrm{eV})$. The cut-off energy for the plane-wave basis was set to $30 \mathrm{Ry}(408 \mathrm{eV})$. The integration in the Brillouin zone (BZ) was done on special k-points determined according to the Monkhorst-Pack scheme using a mesh $\left(\begin{array}{lll}2 & 2 & 1\end{array}\right)$. All initial structures were optimized by simultaneously relaxing the supercell basis vectors and the atomic positions inside the supercell using the Broyden-Fletcher-Goldfarb-Shanno (BFGS) algorithm [35]. The relaxation of the atomic coordinates and of the supercell was considered to be complete when atomic forces were $<1.0 \mathrm{mRy} / \mathrm{Bohr}(25.7 \mathrm{meV} / \AA$ ) $)$, stresses were smaller than $0.05 \mathrm{GPa}$, and the total energy during the structural optimization iterative process was changing by $<0.1 \mathrm{mRy}(1.36 \mathrm{meV})$. In the large supercell calculations, the chosen reduced energy cut-off and the mesh of k-points were used in order to spare computing time without compromising accuracy [36]. Such computational conditions were proved to be quite justified [37]. In particular, the calculated lattice parameters for TiN and $\mathrm{ZrN}$ were $4.238 \AA$ and $4.579 \AA$, respectively. These values are very close to the experimental lattice constants of 4.240 ̊̊ [PDF 065-0715] and 4.575 $̊$ [PDF 065-0972], respectively.

The tensile stress-strain relations were calculated by: 1) elongating the supercells along the c-axis (the (001)-direction in the hexagonal supercells, or the (111) direction in the B1-lattice) in an incremental step, 2) fixing of the $\mathrm{c}$ basis vector and 3) simultaneously relaxing the aand b-basis cell vectors and the positions of the atoms within the supercell $[37,38]$.

\section{Results and Discussion}

\subsection{Elemental Composition}

TEM images of the cross-sections of the TiN/ZrN coatings are presented in the Fig. 1. Studied coatings have rather good planarity of the deposited layers without droplet defects between TiN and ZrN layers and inside them. The layers are clearly visible; they also have clear boundaries and do not intersect.

Compositional analysis for TiN/ZrN coatings before and after annealing is shown in Fig. 2. We should point, that energy-dispersion spectra are typical for all samples (not presented in this article). Stoichiometry of the composition of the TiN/ZrN coatings can be seen from it. Changes of elemental composition in the surface layers of the studied coatings were observed after annealing, see Table 1. SEM was used for studies of changes in the near-surface layers of the annealed coatings. Changes of elemental composition occurred due to annealing, we observed the content of oxygen atoms around 35 at.\%. Penetration of oxygen into iterative nitride layers and forming of the titanium and zirconium dioxides in the near-surface layers are responsible for significant structure changes of TiN and $\mathrm{ZrN}$ layers due to substitution of nitrogen atoms by oxygen ones.

Increasing of the specific volume of nitrides phases during oxidation led to bending of the layers, their lamination and loss of continuity, see Fig. 3. Main volume changes occurred in TiN layers, while columnar structures were observed in ZrN layers, which led to increasing of fragility of ZrN layers. TiN layers were compressed and compacted due to their high density. Thus, compensating strain appeared in the plane of growth of such layers, and it was responsible for their fragility. The 
a)

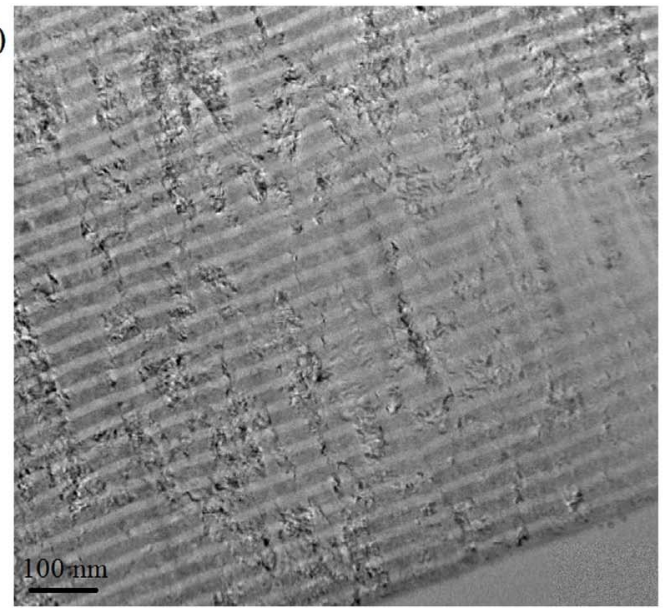

b)

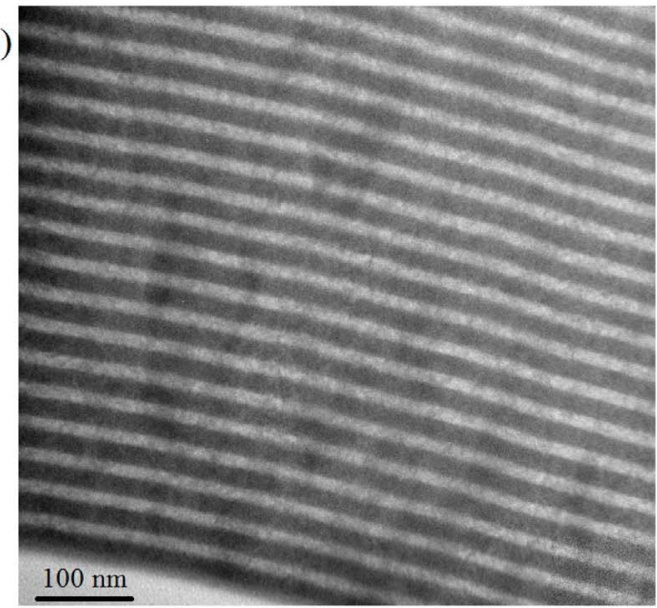

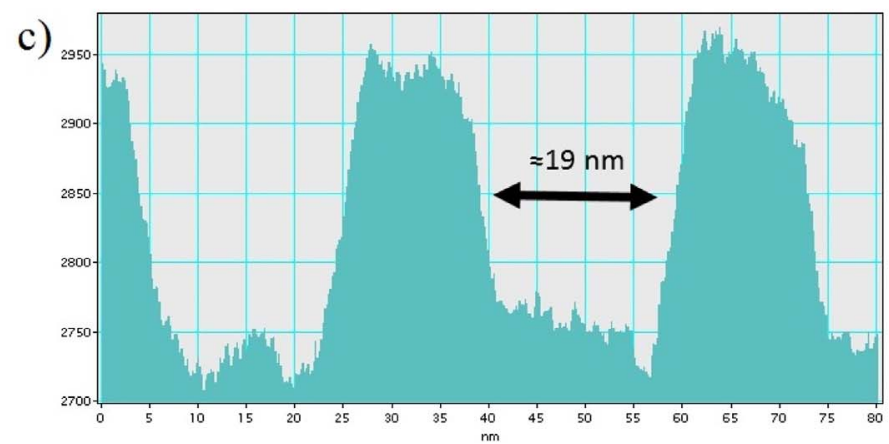

Fig. 1. TEM images of the cross-sections of the TiN/ZrN sample before (a) and after annealing (b). Thickness of TiN layer (c).

interphase boundary was the main separation point because of decreasing of adhesive bonds due to oxidation of the TiN and ZrN layers, which led to forming of phases with different lattice types (cubic in $\mathrm{Zr}$ base layers and tetragonal in Ti based layers).

Depth profile SIMS analysis for TiN/ZrN samples is shown in Fig. 4 and presents the entire structure of the as-deposited TiN/ZrN coating (Fig. 4a) and annealed (Fig. 4b) TiN/ZrN coating, with first several bilayers sequentially separated. Sputtering with $\mathrm{Ar}^{+}$beam of $1.72 \mathrm{keV}$ energy allows the removal of all the successive layers and registering ionic currents of characteristic secondary ions. Visible oscillations of the $\mathrm{Ti}^{+}$and $\mathrm{Zr}^{+}$positive ion currents result from ion etching of the successive layers of TiN and $\mathrm{ZrN}$. Nitrogen detection in SIMS analysis was not allowed for TiN/ZrN system. Depth profile analysis for annealed sample (Fig. 4b) was performed with two sputtering rates: $10 \mathrm{~nm} / \mathrm{min}$ (left image) and $30 \mathrm{~nm} / \mathrm{min}$ (right image). In the range of one micrometer $\mathrm{Ti}$ ion current signal
Table 1

Elemental composition of as-deposited and annealed TiN/ZrN coatings.

\begin{tabular}{|c|c|c|c|c|}
\hline \multirow[t]{2}{*}{ Element } & \multicolumn{2}{|l|}{$\mathrm{wt} \%$} & \multicolumn{2}{|l|}{ at.\% } \\
\hline & As-deposited & Annealed & As-deposited & Annealed \\
\hline $\mathrm{Zr}$ & 50.47 & 67.08 & 21.8 & 35.4 \\
\hline $\mathrm{Ti}$ & 29.53 & 16.92 & 24.2 & 16.6 \\
\hline $\mathrm{N}$ & 20 & 4 & 54 & 13 \\
\hline $\mathrm{O}$ & & 12 & & 35 \\
\hline Total & 100.00 & 100.00 & 100.00 & 100.00 \\
\hline
\end{tabular}

decreased two times while $\mathrm{Zr}$ ion current signal increased four times. We can conclude that segregation occurred within the annealed structure, which led to TiN enrichment and $\mathrm{ZrN}$ depletion within $1 \mu \mathrm{m}$ thickness of the annealed sample. a)

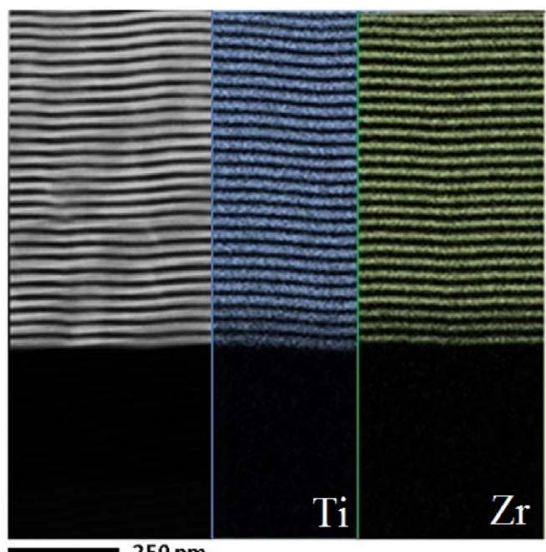

b)

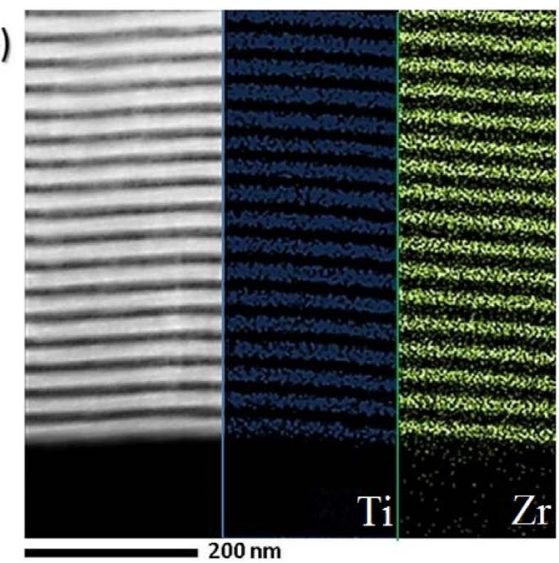

Fig. 2. Compositional analysis spectra of the TiN/ZrN samples before (a) and after (b) annealing. 
a)

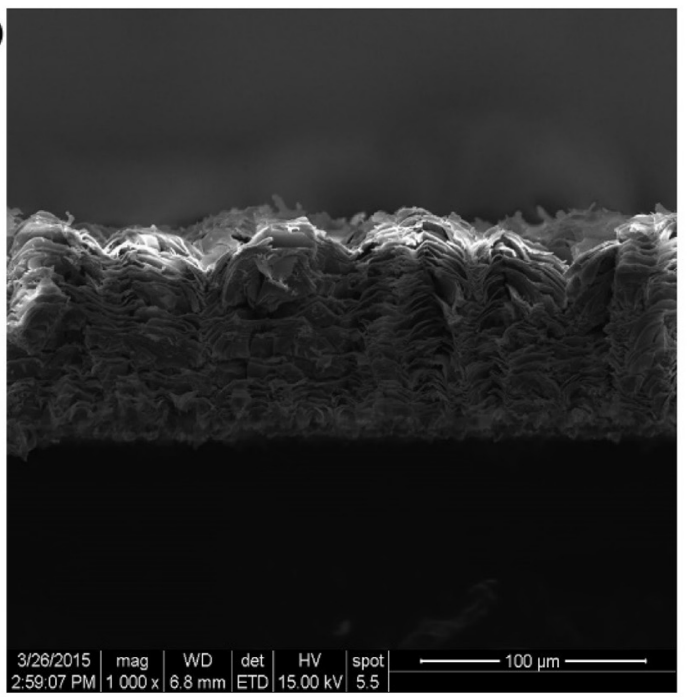

b)

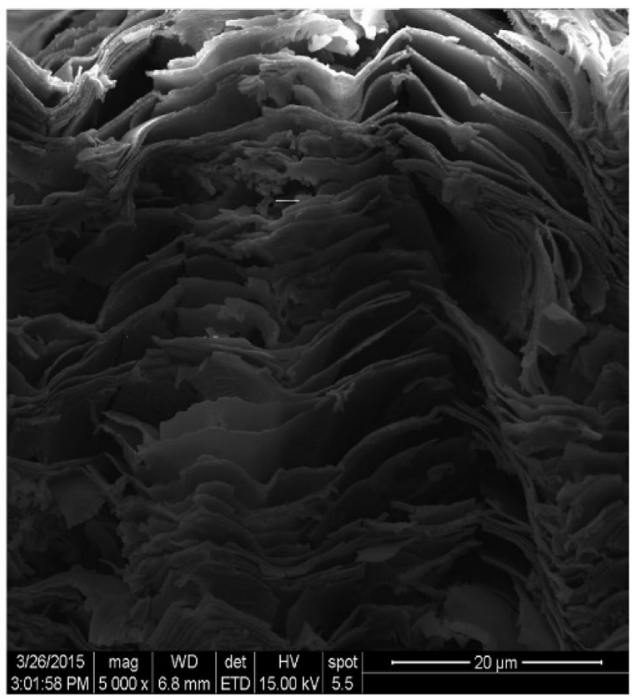

Fig. 3. SEM images of the multilayered TiN/ZrN coatings after annealing at the temperature $700{ }^{\circ} \mathrm{C}$ : cross-section view (a) and surface view (b)

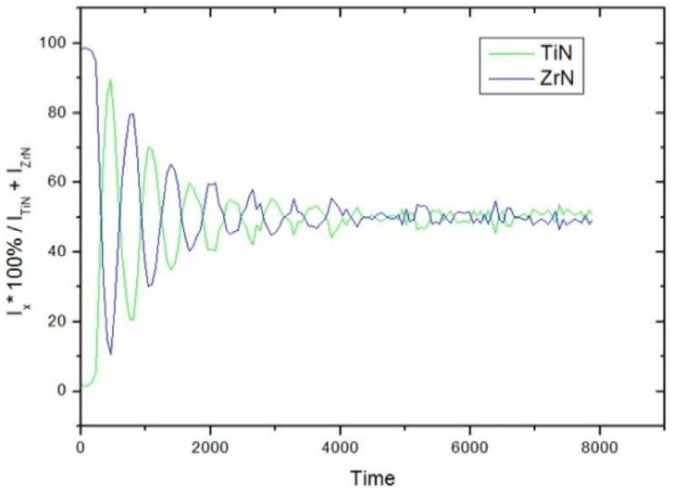

(a)

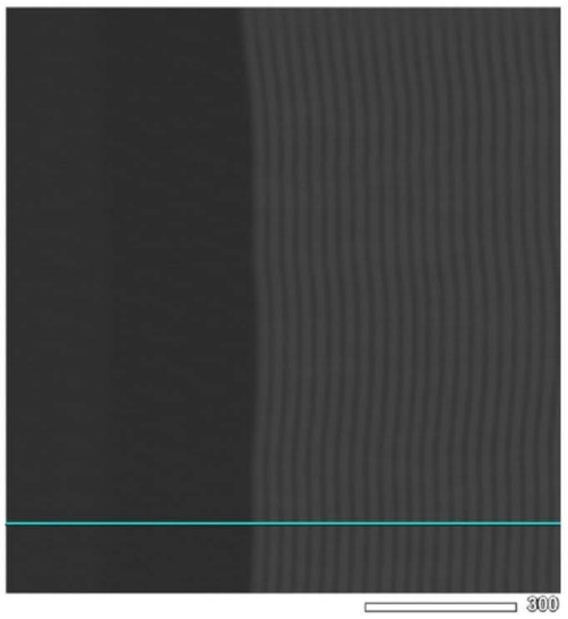

(c)

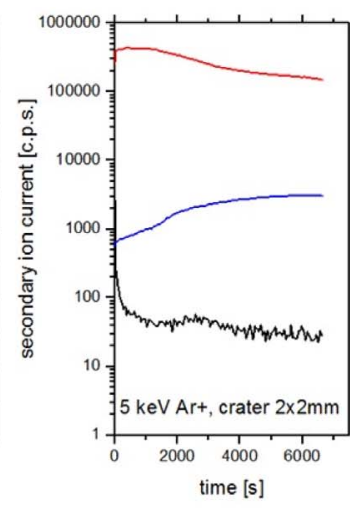

(b)
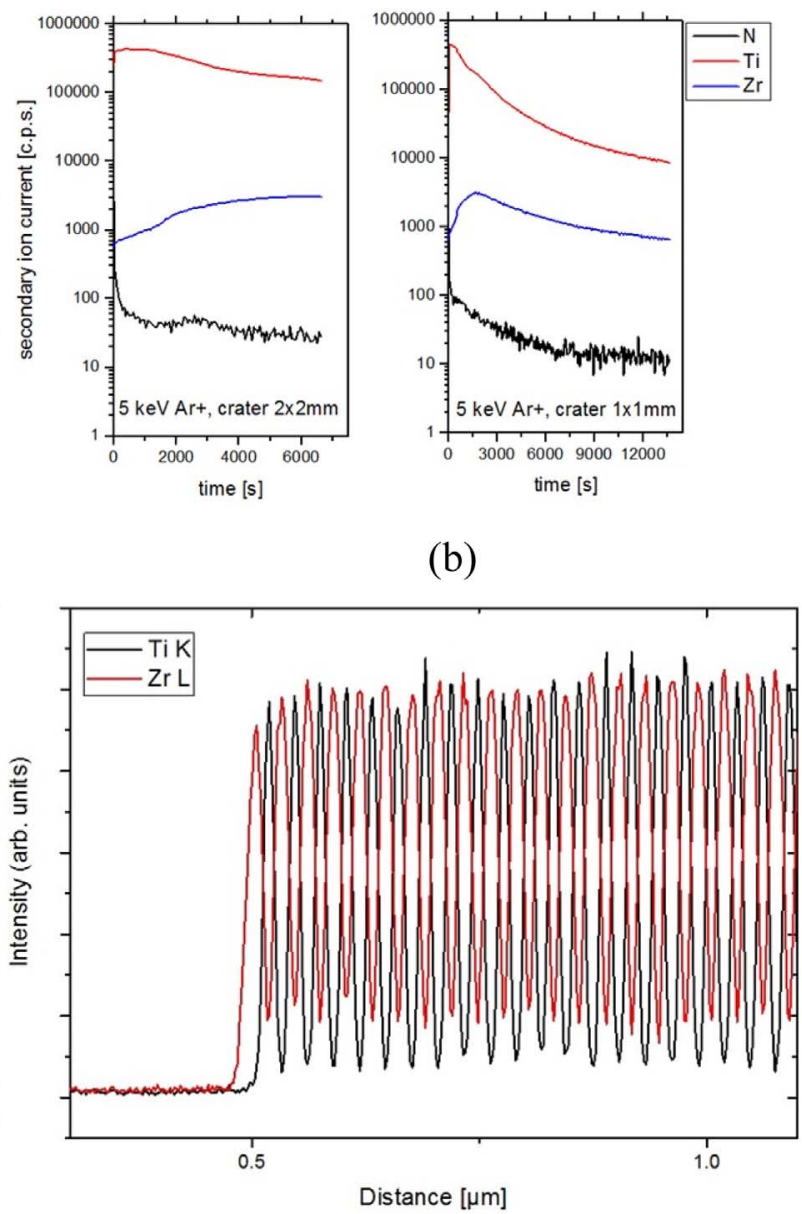

(d)

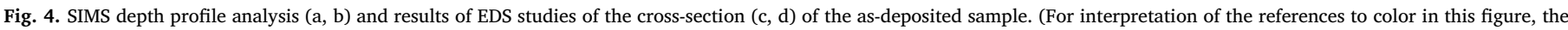
reader is referred to the web version of this article.) 

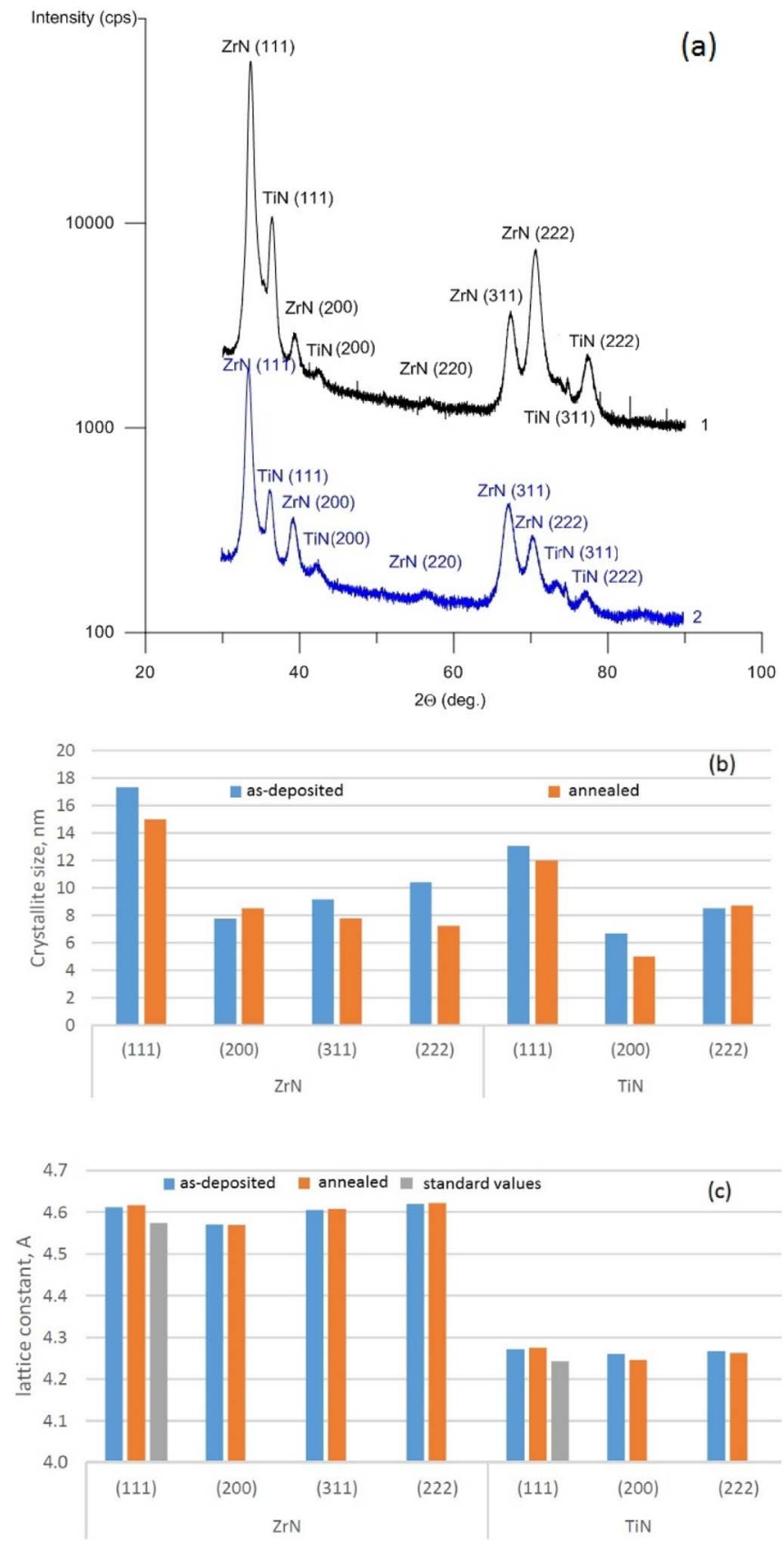

Fig. 5. X-ray diffractograms of multilayered TiN/ZrN coatings before (1) and after (2) annealing (a); calculated sizes of crystallites (b) and lattice constants (c).

Compositional survey of the cross-section of TiN/ZrN sample (see Fig. 4c and d, EDS studies were made along blue line): $\mathrm{Zr}$ content 50.6 at. $\%$, Ti content 33.94 at.\%.

\subsection{Structural Analysis}

Typical diffraction patterns of the multilayered sample before and after annealing are presented in the Fig. 5. Thickness of the informative layer was around $4 \mu \mathrm{m}$. We clearly see layers with cubic TiN and $\mathrm{ZrN}$ phases (of the $\mathrm{NaCl}$ structure type), which are characterized by preferred orientation of crystallites with the [111] axis, perpendicular to the plane of growth. Such preferred orientation with the [111] axis was formed at the beginning stage of growth for both TiN and ZrN crystallites, probably due to compressive stresses [24]. From XRD studies we obtained the average size of crystallites using Scherrer equation, a)
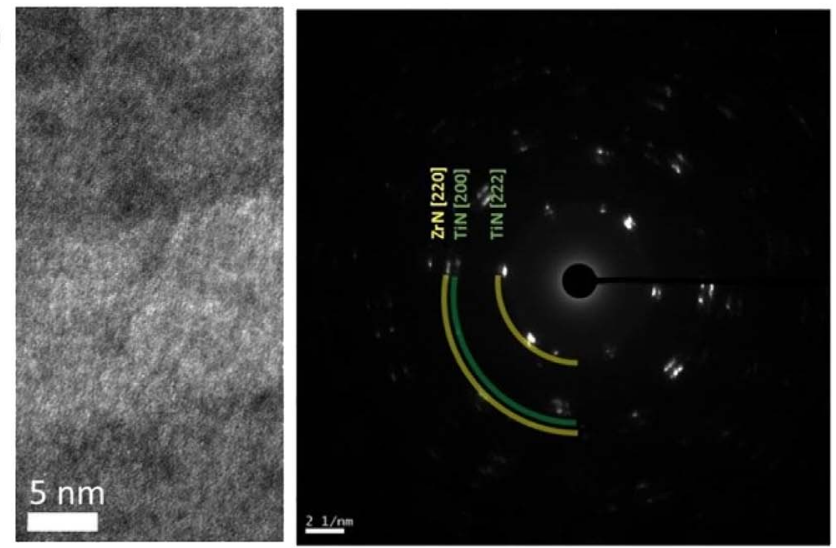

b)
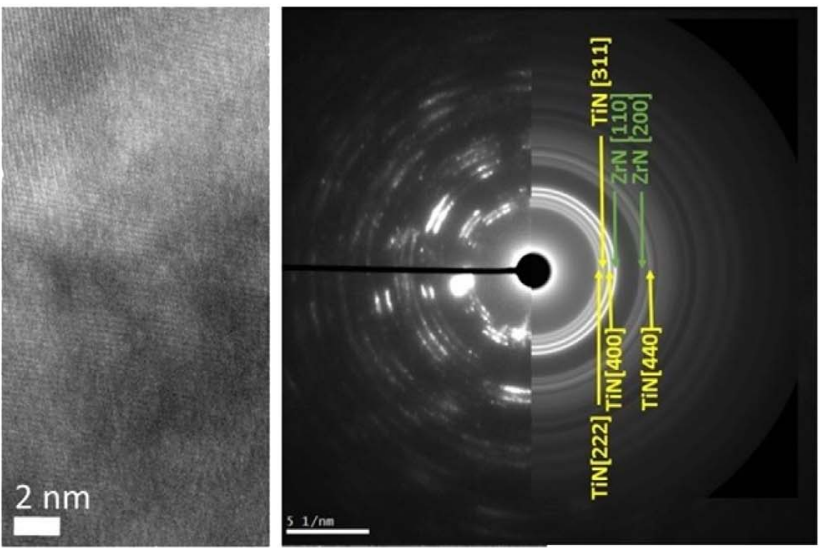

Fig. 6. TEM images and diffraction patterns of the TiN/ZrN coatings, collected on selected area, before (a) and after (b) annealing.

that relates the size of crystallites in a solid to the broadening of a peak in a diffraction pattern. Thus, the average size of crystallites was 8.5-13 nm for TiN phase and 7.7-17.3 nm for ZrN in the as-deposited sample, and $8.7-12 \mathrm{~nm}$ for TiN phase and $7.2-15 \mathrm{~nm}$ for $\mathrm{ZrN}$ phase in annealed sample. Thus, we can conclude, that annealing led to small decreasing of the size of crystallites, see Fig. 5b.

Calculating of lattice parameters showed, that they are a little bit larger in comparison with standard values ( $1 \%$ larger for $\mathrm{ZrN}$ and $0.6 \%$ larger for TiN), see Fig. 5c. It was probably caused by compressive stresses in the deposited coatings, compression of coatings in a direction parallel to the surface and stretching along the normal to the surface.

The cross-sectional TEM images and the selected area diffraction patterns (SADP) taken from the TiN/ZrN samples before (Fig. 6a) and after (Fig. 6b) annealing are shown in Fig. 6. Crystalline structures are clearly observed. The samples were highly polycrystalline with large 10-20 nm crystals, HRTEM revealed highly ordinated laminates with strong crystalline peaks. The crystalline planes were also very ordinated and demonstrated an excellent coordinated growth. $\mathrm{ZrN}$ and TiN diffraction planes were identified using the DiffractTools plugin software [39]. Well defined laminates are observed.

\subsection{Mechanical and Tribological Properties}

Hardness is the most universal characteristic, which allow estimating mechanical properties of the coatings. The main differences between methods of micro- and nanoindentation, which were applied to our coatings during mechanical tests, is the maximal allowed penetration depth of indenter. Thus, for microindentation investigations, value of the indenter's load was less or equal $2 \mathrm{~N}$, and penetration depth was more, than $0.2 \mathrm{~mm}$. For nanoindentation investigations penetration depth was $<0.2 \mathrm{~mm}$. On different ranges of penetration depth various 
Table 2

Results of measurements of microhardness (H), Vickers hardness (HV) and elastic modulus (E).

\begin{tabular}{|c|c|c|c|c|c|c|c|}
\hline TiN/ZrN sample & $\mathrm{H}_{\mathrm{m}}, \mathrm{GPa}$ & $\mathrm{Dev}_{\mathrm{Hm}}, \mathrm{GPa}$ & $\mathrm{H}_{\mathrm{n}}, \mathrm{GPa}$ & $\operatorname{Dev}_{\mathrm{Hn}}, \mathrm{GPa}$ & $\mathrm{HV}$ & $\mathrm{E}, \mathrm{GPa}$ & $\operatorname{Dev}_{\mathrm{E}}, \mathrm{GPa}$ \\
\hline As-deposited & 42 & \pm 2.31 & 34.5 & \pm 1.92 & 242 & 347.39 & \pm 8.93 \\
\hline \multirow[t]{2}{*}{ After annealing at a temperature $700{ }^{\circ} \mathrm{C}$ in air } & 15 & \pm 1.22 & 6.58 & \pm 0.79 & 202 & 153.43 & \pm 20.08 \\
\hline & $42^{\mathrm{a}}$ & & & & & 362.5 & \pm 11.2 \\
\hline Single-layer TiN & 28 & \pm 0.5 & & & & 251 & \\
\hline Single-layer ZrN & 22.7 & \pm 1.7 & & & & 450 & \\
\hline
\end{tabular}

${ }^{\text {a }}$ After removal of the oxidized part of the coating (4-5 $\mu \mathrm{m}$ in thickness) by mechanical polishing.

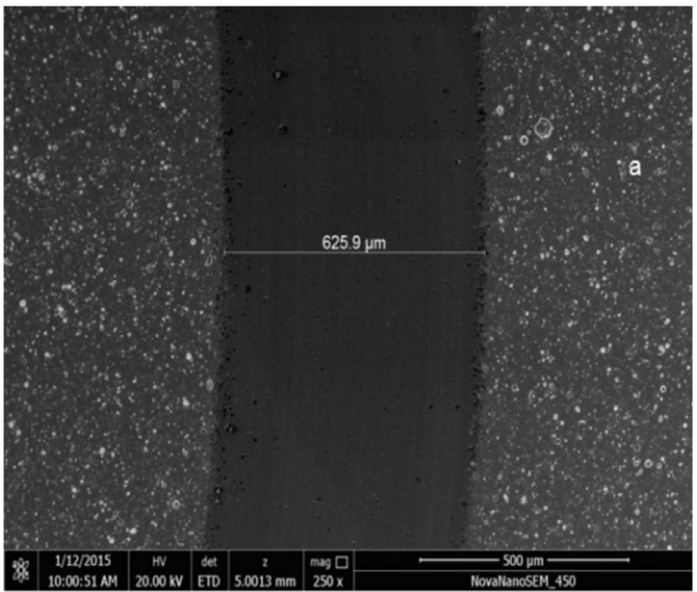

a)

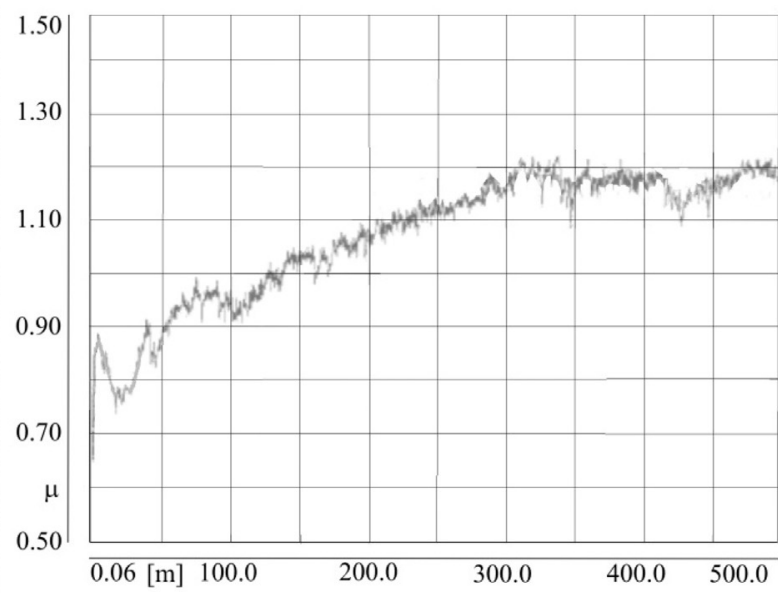

b)

Fig. 7. Friction track (a) and friction coefficient (b) of the as-deposited multilayered TiN/ZrN coatings.

influence of size effect can be observed, and this effect can also influence the obtained values of hardness. That's why values of microhardness and nanohardness will differ for the same samples. In addition, the difference between microhardness and nanohardness can be also caused by usage of the dynamical penetration mode of the indenter during nanoindentation tests. In Table 2 we show the results of measurements of microhardness $\left(\mathrm{H}_{\mathrm{m}}\right)$ and nanohardness $\left(\mathrm{H}_{\mathrm{n}}\right)$, Vickers hardness (HV) and elastic modulus (E), as well as average deviation of their values. Values of micro-hardness and elasticity modulus for singlelayer nanostructured TiN and $\mathrm{ZrN}$ coatings, fabricated using vacuumarc evaporation, are presented in Table 2 for comparison. One can see that hardness was very high for not annealed samples and reached the value $34.5 \mathrm{GPa}$, which is close to superhardness. In according to the works of other researchers [40,41], hardness of single-layer TiN or $\mathrm{ZrN}$ coatings is $22-28 \mathrm{GPa}$. Thus, we can conclude, that deposition of

Table 3

Tribological properties of single-layered TiN, Ti-Si-N, Ti-Zr-Si-N, taken from [42], and multilayered TiN/ZrN coatings.

\begin{tabular}{lllll}
\hline Coatings & $\begin{array}{l}\text { Temperature } \\
\text { tests, }{ }^{\circ} \mathrm{C}\end{array}$ & $\begin{array}{l}\text { Wear factor of } \\
\text { the counterbody } \\
\left(\mathrm{mm}^{3} / \mathrm{nm}\right)\end{array}$ & $\begin{array}{l}\text { Wear factor of } \\
\text { the sample } \\
\left(\mathrm{mm}^{3} / \mathrm{nm}\right)\end{array}$ & $\begin{array}{l}\text { Friction } \\
\text { coefficient }\end{array}$ \\
\hline TiN & 30 & $6.75 \times 10^{-5}$ & $3.30 \times 10^{-5}$ & 0.81 \\
& 300 & $3.62 \times 10^{-5}$ & $3.51 \times 10^{-5}$ & 0.87 \\
& 500 & $5.16 \times 10^{-5}$ & $3.83 \times 10^{-5}$ & 0.91 \\
Ti-Si-N & 30 & $7.69 \times 10^{-5}$ & $3.28 \times 10^{-5}$ & 0.88 \\
& 300 & $2.63 \times 10^{-5}$ & $3.49 \times 10^{-5}$ & 0.82 \\
& 500 & $1.95 \times 10^{-5}$ & $2.75 \times 10^{-5}$ & 0.69 \\
Ti-Zr-Si-N & 30 & $7.59 \times 10^{-5}$ & $1.93 \times 10^{-5}$ & 0.80 \\
& 300 & $2.22 \times 10^{-5}$ & $3.14 \times 10^{-5}$ & 0.71 \\
& 500 & $1.49 \times 10^{-5}$ & $2.81 \times 10^{-5}$ & 0.58 \\
TiN/ZrN & 30 & $1.9 .10^{-6}$ & $1.3 \times 10^{-5}$ & 1.0 \\
& 700 (in air) & $1.21 \times 10^{-6}$ & $1.56 \times 10^{-5}$ & 0.435 \\
\hline
\end{tabular}

multilayered TiN/ZrN coatings led to significant increasing of hardness. Annealed samples demonstrated much lower hardness.

Due to the results of tribological tests of as-deposited TiN/ZrN samples under room temperature we can claim, that their wear coefficient paired with the $\mathrm{Al}_{2} \mathrm{O}_{3}$ counterbody was quite high, i.e. all deposited coatings demonstrate good wear resistance. Friction coefficient was 0.56 at the starting moment of the tribological tests and became equal to 1.0 during tests, whereas wear factor was $1.9 \cdot 10^{-6}$ and $1.3 \cdot 10^{-5} \mathrm{~mm}^{3} \cdot \mathrm{N}^{-1} \cdot \mathrm{mm}^{-1}$ for counterbody and tested sample respectively. Chipping, cracking and peeling of the coatings were not observed during friction tests, see Fig. 7, where the typical image of

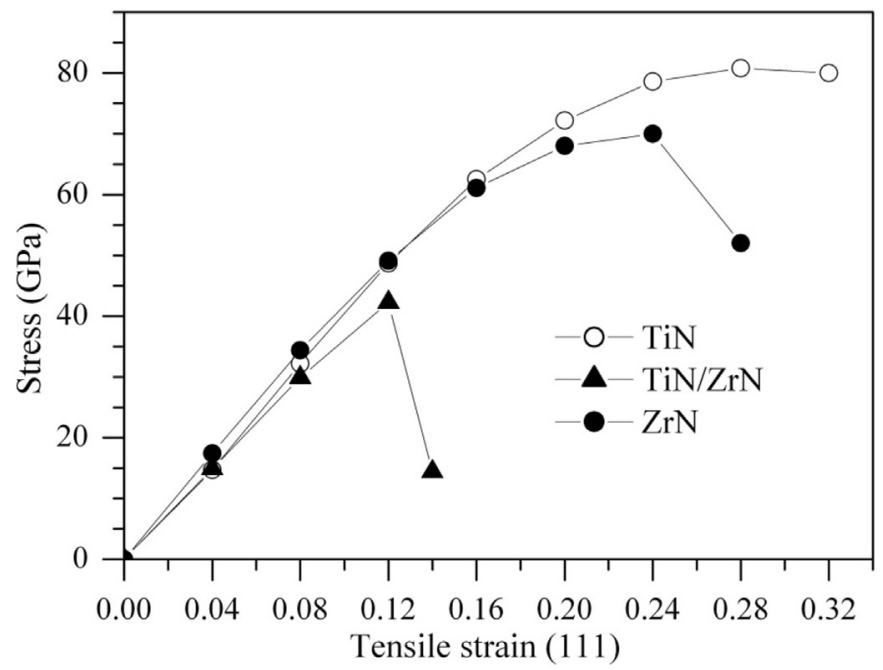

Fig. 8. Tensile stress-strain curves for the $\operatorname{TiN}(111)$, $\operatorname{TiN}(111) / \operatorname{ZrN}(111)$ and $\operatorname{ZrN}(111)$ structures. 

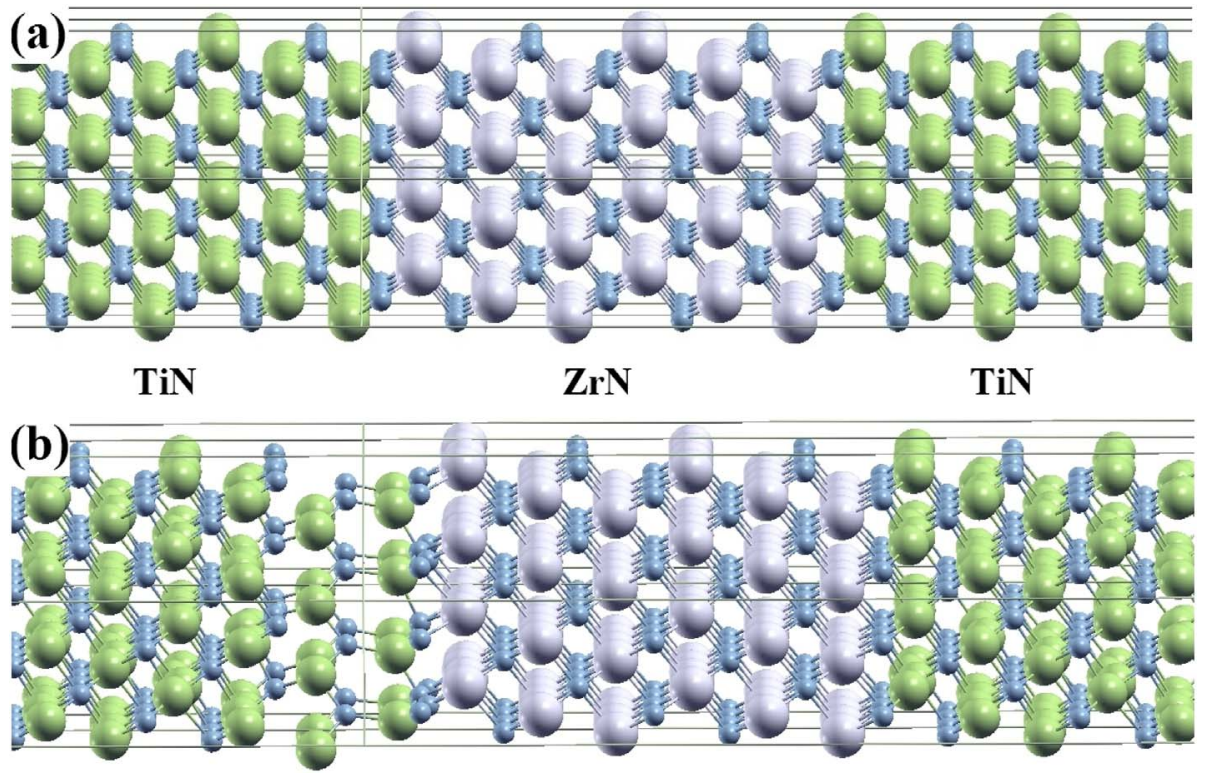

Fig. 9. Atomic configurations of the $\mathrm{TiN}(111) / \mathrm{ZrN}(111)$ multilayer under tensile strain $\varepsilon=0$ (a) and $\varepsilon=0.16$ (b). wear track is presented. Friction tracks are characterized by absence of burrs, cleavages and radial cracks, indicating the high quality and adhesive strength of the coatings. We found good adhesion of the coatings to substrates and no plastic deformation was observed during tests, the observed wear was rather typical for soft metals. Values of friction coefficient $\mu$ for the as-deposited samples monotonically increased along the friction distance. Results of tribological studies are summarized in the Table 3 in comparison with the results for single-layered TiN, Ti-Si-N and T-Zr-Si-N coatings, being published in the work [42]. Friction coefficient of the as-deposited multilayered TiN/ZrN coatings is significantly higher than of single-layered TiN, Ti-Si-N and T-Zr-Si-N coatings, nevertheless its wear factor is lower.

We should point, that friction coefficient of the annealed coatings decreased almost two times. It can be explained by the fact, that oxide film was not removed from the surface of the annealed coatings before tribological tests. Such oxide films are known for their low friction coefficient.

\subsection{Results of theoretical investigations}

In Fig. 8 we show the tensile stress-strain relations of the tree structures under investigation. One can see that the ideal tensile strength (maximum stress) for the TiN/ZrN multilayer does not exceed that for TiN. It follows that the observed strength enhancement in the $\mathrm{TiN} / \mathrm{ZrN}$ nanolayered films is not related to the strengthening of the bonds due to the formation of the multilayer heterostructure. Fig. 9 shows the atomic configurations of the $\mathrm{TiN}(111) / \mathrm{ZrN}(111)$ multilayer at different stages of uniaxial tension. The failure of the multilayer occurs owing to the structural transformation in the TiN block near the interface (cf. Fig. 9). This can be explained taking into account the fact that, in the $\mathrm{TiN}(111) / \mathrm{ZrN}(111)$ multilayer, the TiN block is under tensile stress, whereas the $\mathrm{ZrN}$ block is under compressive stress. For the unstrained multilayer, the following changes in the metal-nitrogen bond lengths relatively those in TiN and $\mathrm{ZrN}$ take place (in $\AA$ ): $\mathrm{N} \leftarrow$ $+0.037 \rightarrow \mathrm{Ti} \leftarrow+0.025 \rightarrow \mathrm{N} \rightarrow-0.011 \leftarrow \mathrm{Zr} \rightarrow-0.035 \leftarrow \mathrm{N}$, where the arrows " $\leftarrow \rightarrow$ " and " $\rightarrow \leftarrow$ " denote the bond length elongation and shortening, respectively. When the multilayer system is elongated, the supercell volume increases. As a result, the Ti-N bonds near the interface weaken, and the interfacial $\mathrm{Zr}-\mathrm{N}$ bonds strengthen.

We would like to note also one important feature. The calculated tensile ideal strengths for the $\mathrm{TiN}(001)$ and $\mathrm{ZrN}(001)$ structures were $30 \mathrm{GPa}$ and $24 \mathrm{GPa}$, respectively $[43,44]$. These values are lower than the tensile ideal strength of $42 \mathrm{GPa}$ for the $\operatorname{TiN}(111) / \mathrm{ZrN}(111)$ multilayer. This points to that the strength enhancement observed for the deposited TiN/ZrN nanolayered films (compared to TiN and $\mathrm{ZrN}$ films) can be assigned also to the (111) crystallite orientation (cf. Fig. 5), provided the TiN and $\mathrm{ZrN}$ films have the (001) preferable crystallite orientation.

\section{Conclusions}

Nanoscale two-phase multilayered TiN/ZrN coatings were deposited on steel substrates using vacuum-arc evaporation method. Total thickness of the coatings was $19 \mu \mathrm{m}$, while bilayer thickness was about $39 \mathrm{~nm}$. Cubic TiN and $\mathrm{ZrN}$ phases (of the $\mathrm{NaCl}$ structure type) with preferred orientation of crystallites with the [111] axis, perpendicular to the plane of growth, were observed in the deposited coatings. Several samples were annealed up to $700{ }^{\circ} \mathrm{C}$ in air, which led to oxidation of the near-the-surface layers of the multilayer coatings. Texture [111] in the surface layers prevented the inner layers of the coatings from oxidation, so TiN/ZrN multilayer coatings demonstrate good resistance to oxidation. As-deposited coatings demonstrated quite high hardness about $42 \mathrm{GPa}$ due to considerable influence of the sizes of the interphase boundary, while hardness of the annealed ones reduced. Thus, this coating system almost attains the superhard grade. The results of tribological tests showed that durability of the steel substrates significantly increased after the deposition of multilayered TiN/ZrN coating. Friction coefficient of the multilayered TiN/ZrN coatings is significantly higher than of single-layered TiN, Ti-Si-N and T-Zr-Si-N coatings, nevertheless its wear factor is lower.

First-principles calculations of the tensile stress-strain relations for the TiN(111), TiN(111)/ZrN(111) and $\mathrm{ZrN}(111)$ structures were carried out. The results reveal that the tensile ideal strength for the multilayer is lower as compared to the ideal tensile strengths for TiN and $\mathrm{ZrN}$, which indicates that the formation of the multilayer heterostructure does not lead to its strengthening from the point view of chemical bonding. Based on the results of both the experimental and theoretical studies, the observed strength enhancement of the deposited TiN/ZrN nanolayered films can be assigned to the TiN/ZrN interfaces that prevent dislocation movement [45] as well to the (111) preferable crystalline orientation.

\section{Acknowledgements}

This work was done under the aegis of Ukrainian State Budget Programs: "Development of material science fundamentals of structure 
engineering of vacuum-plasma superhard coatings with given functional properties" (registration number 0115U000682) and "Development of perspective nanostructured multilayered coatings with enhanced physical-mechanical and tribological properties" (registration number 0116U006816).

\section{References}

[1] A. Madan, X. Chu, S.A. Barnett, Growth and characterization of epitaxial Mo/NbN superlattices, Appl. Phys. Lett. 68 (1996) 2198, http://dx.doi.org/10.1063/1. 116011.

[2] J. Lao, N. Shao, F. Mei, G. Li, M. Gu, Mutual promotion effect of crystal growth in TiN/SiC nanomultilayers, Appl. Phys. Lett. 86 (2005) 11902, , http://dx.doi.org/ 10.1063/1.1844045.

[3] H. Söderberg, M. Odén, T. Larsson, L. Hultman, J.M. Molina-Aldareguia, Epitaxial stabilization of cubic-SiN ${ }_{x}$ in TiN/ $/ \mathrm{SiN}_{\mathrm{x}}$ multilayers, Appl. Phys. Lett. 88 (2006) 191902, , http://dx.doi.org/10.1063/1.2202145.

[4] F. Wang, D. Holec, M. Odén, F. Mücklich, I.A. Abrikosov, F. Tasnádi, Systematic ab initio investigation of the elastic modulus in quaternary transition metal nitride alloys and their coherent multilayers, Acta Mater. 127 (2017) 124-132, http://dx. doi.org/10.1016/j.actamat.2017.01.017.

[5] E. Ribeiro, L. Rebouta, S. Carvalho, F. Vaz, G.G. Fuentes, R. Rodriguez, M. Zazpe, E. Alves, P. Goudeau, J.P. Rivière, Characterization of hard DC-sputtered Si-based TiN coatings: the effect of composition and ion bombardment, Surf. Coat. Technol. 188-189 (2004) 351-357, http://dx.doi.org/10.1016/j.surfcoat.2004.08.020.

[6] M. Benda, J. Musil, Plasma nitriding enhanced by hollow cathode discharge - a new method for formation of superhard nanocomposite coatings on steel surfaces, Vacuum 55 (1999) 171-175, http://dx.doi.org/10.1016/S0042-207X(99)00145-1.

[7] T. An, M. Wen, L.L. Wang, C.Q. Hu, H.W. Tian, W.T. Zheng, Structures, mechanical properties and thermal stability of TiN/SiN $\mathrm{x}_{\mathrm{x}}$ multilayer coatings deposited by magnetron sputtering, J. Alloys Compd. 486 (2009) 515-520, http://dx.doi.org/10. 1016/j.jallcom.2009.06.194.

[8] C.J. Tavares, L. Rebouta, B. Almeida, J. Bessa e Sousa, Structural characterization of multilayered sputtered TiN/ZrN coatings, Surf. Coat. Technol. 100-101 (1998) 65-71, http://dx.doi.org/10.1016/S0257-8972(97)00589-6.

[9] A.D. Pogrebnjak, O.V. Bondar, B. Zhollybekov, S. Konstantinov, P. Konarski, V.M. Beresnev, A.I. Kupchishin, Influence of the bilayer thickness of nanostructured multilayer MoN/CrN coating on its microstructure, hardness, and elemental composition, Phys. Solid State 59 (2017) 1798-1802.

[10] B.O. Postolnyi, V.M. Beresnev, G. Abadias, O.V. Bondar, L. Rebouta, J.P. Araujo, A.D. Pogrebnjak, Multilayer design of $\mathrm{CrN} / \mathrm{MoN}$ protective coatings for enhanced hardness and toughness, J. Alloys Compd. 725 (2017) 1188-1198, http://dx.doi. org/10.1016/j.jallcom.2017.07.010.

[11] A.D. Pogrebnjak, A.A. Bagdasaryan, A. Pshyk, K. Dyadyura, Adaptive multicomponent nanocomposite coatings in surface engineering, Physics-Uspekhi 60 (2017) 629-652, http://dx.doi.org/10.3367/UFNe.2016.12.038018.

[12] M. Braic, M. Balaceanu, A.C. Parau, M. Dinu, A. Vladescu, Investigation of multilayered TiSiC/NiC protective coatings, Vacuum 120 (2015) 60-66, http://dx.doi. org/10.1016/j.vacuum.2015.06.019.

[13] M. Wen, Q.N. Meng, C.Q. Hu, T. An, Y.D. Su, W.X. Yu, W.T. Zheng, Structure and mechanical properties of $\delta$-NbN/SiN ${ }_{\mathrm{x}}$ and $\delta$ '-NbN/SiN ${ }_{\mathrm{x}}$ nano-multilayer films deposited by reactive magnetron sputtering, Surf. Coat. Technol. 203 (2009) 1702-1708, http://dx.doi.org/10.1016/j.surfcoat.2009.01.002.

[14] M. Wen, C.Q. Hu, C. Wang, T. An, Y.D. Su, Q.N. Meng, W.T. Zheng, Effects of substrate bias on the preferred orientation, phase transition and mechanical properties for NbN films grown by direct current reactive magnetron sputtering, J. Appl. Phys. 104 (2008) 23527, , http://dx.doi.org/10.1063/1.2956706.

[15] J. Ming, M. Li, P. Kumar, L.-J. Li, Multilayer approach for advanced hybrid lithium battery, ACS Nano 10 (2016) 6037-6044, http://dx.doi.org/10.1021/acsnano. 6b01626.

[16] M.I. Yousaf, V.O. Pelenovich, B. Yang, C.S. Liu, D.J. Fu, Effect of bilayer period on structural and mechanical properties of nanocomposite TiAlN/MoN multilayer films synthesized by cathodic arc ion-plating, Surf. Coat. Technol. 282 (2015) 94-102, http://dx.doi.org/10.1016/j.surfcoat.2015.10.018.

[17] S.Y. Zhou, V.O. Pelenovich, B. Han, M.I. Yousaf, S.J. Yan, C.X. Tian, D.J. Fu, Effects of modulation period on microstructure, mechanical properties of TiBN/TiN nanomultilayered films deposited by multi arc ion plating, Vacuum 126 (2016) 34-40, http://dx.doi.org/10.1016/j.vacuum.2016.01.007.

[18] L.A. Rocha, E. Ariza, J. Ferreira, F. Vaz, E. Ribeiro, L. Rebouta, E. Alves, A.R. Ramos, P. Goudeau, J.P. Rivière, Structural and corrosion behaviour of stoichiometric and substoichiometric TiN thin films, Surf. Coat. Technol. 180-181 (2004) 158-163, http://dx.doi.org/10.1016/j.surfcoat.2003.10.059.

[19] Y.X. Ou, J. Lin, S. Tong, W.D. Sproul, M.K. Lei, Structure, adhesion and corrosion behavior of CrN/TiN superlattice coatings deposited by the combined deep oscillation magnetron sputtering and pulsed dc magnetron sputtering, Surf. Coat. Technol. 293 (2016) 21-27, http://dx.doi.org/10.1016/j.surfcoat.2015.10.009.

[20] O. Boiko, T.N. Koltunowicz, P. Zukowski, A.K. Fedotov, A.V. Larkin, The effect of sputtering atmosphere parameters on dielectric properties of the ferromagnetic alloy-ferroelectric ceramics nanocomposite $(\mathrm{FeCoZr})_{\mathrm{x}}\left(\mathrm{PbZrTiO}_{3}\right)_{100-\mathrm{x}}$, Ceram.
Int. 43 (2017) 2511-2516, http://dx.doi.org/10.1016/j.ceramint.2016.11.052.

[21] I.A. Svito, A.K. Fedotov, A. Saad, P. Zukowski, T.N. Koltunowicz, Influence of oxide matrix on electron transport in $(\mathrm{FeCoZr})_{\mathrm{x}}\left(\mathrm{Al}_{2} \mathrm{O}_{3}\right)_{1}-\mathrm{x}$ nanocomposite films, $\mathrm{J}$. Alloys Compd. 699 (2017) 818-823, http://dx.doi.org/10.1016/j.jallcom.2017.01. 043.

[22] N.N. Guo, L. Wang, L.S. Luo, X.Z. Li, R.R. Chen, Y.Q. Su, J.J. Guo, H.Z. Fu, Hot deformation characteristics and dynamic recrystallization of the MoNbHfZrTi refractory high-entropy alloy, Mater. Sci. Eng. A 651 (2016) 698-707, http://dx.doi. org/10.1016/j.msea.2015.10.113.

[23] A.D. Pogrebnjak, D. Eyidi, G. Abadias, O.V. Bondar, V.M. Beresnev, O.V. Sobol, Structure and properties of arc evaporated nanoscale TiN/MoN multilayered systems, Int. J. Refract. Met. Hard Mater. 48 (2015) 222-228, http://dx.doi.org/10. 1016/j.ijrmhm.2014.07.043.

[24] J. Musil, Hard nanocomposite coatings: thermal stability, oxidation resistance and toughness, Surf. Coat. Technol. 207 (2012) 50-65, http://dx.doi.org/10.1016/j. surfcoat.2012.05.073.

[25] S. Hao, B. Delley, S. Veprek, C. Stampfl, Superhard nitride-based nanocomposites: role of interfaces and effect of impurities, Phys. Rev. Lett. 97 (2006) 86102, , http:// dx.doi.org/10.1103/PhysRevLett.97.086102.

[26] C.J. Tavares, L. Rebouta, B. Almeida, J. Bessa, E. Sousa, M.F. Da Silva, J.C. Soares, Deposition and characterization of multilayered TiN/ZrN coatings, Thin Solid Films 317 (1998).

[27] M. Naddaf, B. Abdallah, M. Ahmad, M. A-Kharroub, Influence of $\mathrm{N}_{2}$ partial pressure on structural and microhardness properties of TiN/ZrN multilayers deposited by $\mathrm{Ar} / \mathrm{N}_{2}$ vacuum arc discharge, Nucl. Inst. Methods Phys. Res. B 381 (2016) 90-95, http://dx.doi.org/10.1016/j.nimb.2016.05.029.

[28] M.K. Samani, X.Z. Ding, N. Khosravian, B. Amin-Ahmadi, Y. Yi, G. Chen, E.C. Neyts, A. Bogaerts, B.K. Tay, Thermal conductivity of titanium nitride/titanium aluminum nitride multilayer coatings deposited by lateral rotating cathode arc, Thin Solid Films 578 (2015) 133-138, http://dx.doi.org/10.1016/j.tsf.2015.02.032.

[29] O.V. Bondar, B.A. Postol'nyi, V.M. Beresnev, G. Abadias, P. Chartier, O.V. Sobol, D.A. Kolesnikov, F.F. Komarov, M.O. Lisovenko, A.A. Andreev, Composition, structure and tribotechnical properties of TiN, MoN single-layer and TiN/MoN multilayer coatings, J. Superhard Mater. 37 (2015) 27-38, http://dx.doi.org/10. 3103/S1063457615010050.

[30] Z.X. Yang, X.Y. Kuang, Z.H. Wang, M.M. Zhong, X.F. Huang, The mechanical properties of MoN under high pressure and effect of metallic bonding on its hardness, Solid State Sci. 28 (2014) 20-25, http://dx.doi.org/10.1016/j. solidstatesciences.2013.12.002.

[31] A.D. Pogrebnyak, A.P. Shpak, N.A. Azarenkov, V.M. Beresnev, Structures and properties of hard and superhard nanocomposite coatings, Physics-Uspekhi 52 (2009) 29-54, http://dx.doi.org/10.3367/UFNe.0179.200901b.0035.

[32] P. Giannozzi, S. Baroni, N. Bonini, M. Calandra, R. Car, C. Cavazzoni, D. Ceresoli, G.L. Chiarotti, M. Cococcioni, I. Dabo, A. Dal Corso, S. de Gironcoli, S. Fabris, G. Fratesi, R. Gebauer, U. Gerstmann, C. Gougoussis, A. Kokalj, M. Lazzeri, L. Martin-Samos, N. Marzari, F. Mauri, R. Mazzarello, S. Paolini, A. Pasquarello, L. Paulatto, C. Sbraccia, S. Scandolo, G. Sclauzero, A.P. Seitsonen, A. Smogunov, P. Umari, R.M. Wentzcovitch, QUANTUM ESPRESSO: a modular and open-source software project for quantum simulations of materials, J. Phys. Condens. Matter. 21 (2009) 395502, , http://dx.doi.org/10.1088/0953-8984/21/39/395502.

[33] D. Vanderbilt, Soft self-consistent pseudopotentials in a generalized eigenvalue formalism, Phys. Rev. B 41 (1990) 7892-7895, http://dx.doi.org/10.1103/ PhysRevB.41.7892.

[34] J.P. Perdew, K. Burke, M. Ernzerhof, Generalized gradient approximation made simple, Phys. Rev. Lett. 77 (1996) 3865-3868.

[35] S.R. Billeter, A. Curioni, W. Andreoni, Efficient linear scaling geometry optimization and transition-state search for direct wavefunction optimization schemes in density functional theory using a plane-wave basis, Comput. Mater. Sci. 27 (2003) 437-445, http://dx.doi.org/10.1016/S0927-0256(03)00043-0.

[36] V. Ivashchenko, S. Veprek, A. Pogrebnjak, B. Postolnyi, First-principles quantum molecular dynamics study of $\mathrm{Ti}_{\mathrm{x}} \mathrm{Zr}_{1}-{ }_{\mathrm{x}} \mathrm{N}(111) / \mathrm{SiN}_{\mathrm{y}}$ heterostructures and comparison with experimental results, Sci. Technol. Adv. Mater. 15 (2014) 25007, , http:// dx.doi.org/10.1088/1468-6996/15/2/025007.

[37] V.I. Ivashchenko, S. Veprek, P.E.A. Turchi, V.I. Shevchenko, First-principles study of TiN/SiC/TiN interfaces in superhard nanocomposites, Phys. Rev. B 86 (2012) 14110, , http://dx.doi.org/10.1103/PhysRevB.86.014110.

[38] A.D. Pogrebnjak, O.V. Bondar, G. Abadias, V. Ivashchenko, O.V. Sobol, S. Jurga, E. Coy, Structural and mechanical properties of NbN and Nb-Si-N films: experiment and molecular dynamics simulations, Ceram. Int. 42 (2016) 1-14, http://dx.doi. org/10.1016/j.ceramint.2016.04.095.

[39] D.R.G. Mitchell, DiffTools: electron diffraction software tools for DigitalMicrograph $^{\mathrm{Tm}}$, Microsc. Res. Tech. 71 (2008) 588-593, http://dx.doi.org/10. 1002/jemt.20591.

[40] D.S. Stone, K.B. Yoder, W.D. Sproul, Hardness and elastic modulus of TiN based on continuous indentation technique and new correlation, J. Vac. Sci. Technol. A 9 (1991) 2543-2547, http://dx.doi.org/10.1116/1.577270.

[41] A.B. Mei, B.M. Howe, C. Zhang, M. Sardela, J.N. Eckstein, L. Hultman, A. Rockett, I. Petrov, J.E. Greene, Physical properties of epitaxial $\mathrm{ZrN} / \mathrm{MgO}(001)$ layers grown by reactive magnetron sputtering, J. Vac. Sci. Technol. A 31 (2013) 61516, , http:// dx.doi.org/10.1116/1.4825349.

[42] A.D. Pogrebnjak, A.P. Shpak, V.M. Beresnev, D.A. Kolesnikov, Y.A. Kunitskii, O.V. Sobol, V.V. Uglov, F.F. Komarov, A.P. Shypylenko, N.A. Makhmudov, 
A.A. Demyanenko, V.S. Baidak, V.V. Grudnitskii, Effect of thermal annealing in vacuum and in air on nanograin sizes in hard and superhard coatings $\mathrm{Zr}-\mathrm{Ti}-\mathrm{Si}-\mathrm{N}, \mathrm{J}$. Nanosci. Nanotechnol. 12 (2012) 9213-9219, http://dx.doi.org/10.1166/jnn.2012. 6777.

[43] V.I. Ivashchenko, S. Veprek, P.E.A. Turchi, V.I. Shevchenko, J. Leszczynski, L. Gorb, F. Hill, First-principles molecular dynamics investigation of thermal and mechanical stability of the TiN(001)/AlN and $\mathrm{ZrN}(001) / \mathrm{AlN}$ heterostructures, Thin Solid Films
564 (2014) 284-293, http://dx.doi.org/10.1016/j.tsf 2014.05.036.

[44] R.F. Zhang, S.H. Sheng, S. Veprek, First principles studies of ideal strength and bonding nature of AlN polymorphs in comparison to TiN, Appl. Phys. Lett. 91 (2007) 31906, , http://dx.doi.org/10.1063/1.2759265.

[45] S. Veprek, Recent search for new superhard materials: go nano!, J. Vac. Sci. Technol. A 31 (2013) 50822, , http://dx.doi.org/10.1116/1.4818590.

Multilayered vacuum-arc nanocomposite TiN/ZrN coatings before and after annealing: $\mathrm{S}$ tructure, properties, first-principles calculations [Текст] / A. Pogrebnjak, V. Ivashchenko, O . Bondar [та ін.] // Materials Characterization. — 2017. — №134. — C. 55-63. 